\title{
Pensando la interacción en entornos virtuales desde datos empíricos: caminos entre casos y teoría
}

The interaction in virtual environments from empirical data: paths between cases and theory

\section{Pensando na interação em ambientes virtuais a partir de dados empíricos: caminhos entre casos e teoria}

Ana Borgobello*

Citar este artículo así:

Borgobello, A. (2018). Pensando la interacción en entornos virtuales desde datos empíricos: caminos entre casos y teoría. Revista Enfoques, 3(1), 129-158. http://dx.doi.org/

Derechos de autor: Licencia Creative Commons AtribuciónNoComercial-SinDerivadas 4.0 internacional y 2.5 Colombia (CC BYNC-ND 2.5 (O)

Recibido: agosto 16 de 2017

Revisado: agosto 23 de 2017 Aceptado: septiembre 08 de 2017

* El presente artículo está basado en una conferencia dictada en la Universidad de Boyacá, Colombia, en 2017. Por esa razón, reviste características propuestas para el debate, que se retoman aquí a modo de revisiones y conclusiones de lo trabajado. Ana Borgobello es Docente investigadora del Instituto Rosario de Investigaciones en Ciencias de la Educación (IRICE) y de la Facultad de Psicología de la Universidad Nacional de Rosario. Researcher ID: N-3809-2015. Contacto email: borgobello@iriceconicet.gov.ar ORCID: https://orcid.org/o0oo-0002-2340-8127 
Resumen | Este escrito presenta como eje la interacción entre docentes y estudiantes en entornos virtuales, en casos en los que se combina el aula tradicional de clases con el espacio digital. Subyace una preocupación de corte metodológica relativa a la construcción de datos, y otra que apunta a la formación de docentes universitarios en el uso de estas plataformas destinadas a la enseñanza y el aprendizaje. Se utilizan múltiples estrategias metodológicas propias de un enfoque complejo-dialéctico, abordado por una línea de investigación radicada en Rosario, Argentina. Se exponen aquí conclusiones e hipótesis generadas a partir de evidencia empírica de tres estudios realizados: 1) Interacción sociocognitiva en un entorno virtual y rendimiento académico en estudiantes universitarios; 2) Análisis comparativo de la interacción sociocognitiva en un espacio virtual y otro tradicional; y 3) Estudio sobre características de textos escritos en un aula virtual, desde las teorías al caso y viceversa. Se discute la necesidad de volver a pensar el aula como eje de trabajo.

Palabras clave I psicología de la educación, aulas extendidas, interacción sociocognitiva, educación superior, metodologías de investigación.

Abstract | This paper presents the analysis of interaction between professors and students in virtual environments when traditional classes are combined with the digital spaces. A methodological concern -the construction of empirical data- and the training of university teachers in the use of these educational platforms, underlie the manuscript. From a complex-dialectical approach, this line of research, located in Rosario, Argentina, uses multiple methodological strategies in the research job. Conclusions and hypotheses generated from empirical evidence from three studies were exposed: 1) Sociocognitive interaction in a virtual environment and academic performance in university students; 2 ) Comparative analysis of sociocognitive interaction in a virtual space and in a traditional one; and 3) Characteristics of texts written in a virtual classroom: from the theories to the case and vice versa. The need to rethink the classroom as an axis of research work was discussed.

Keywords | educational psychology, blended learning, sociocognitive interaction, university, methodology.

Resumo | Este artigo apresenta o analises da interação entre professores e alunos em ambientes virtuais, quando as classes tradicionais são combinadas com os espaços digitais. Uma preocupação metodológica - a construção de dados empíricos - e a formação de professores universitários no uso dessas plataformas educacionais embasam o manuscrito. A partir de uma abordagem complexo-dialética, esta linha de pesquisa, localizada em Rosário,

\section{E 130}


Argentina, utiliza múltiplas estratégias metodológicas no trabalho de pesquisa. Conclusões e hipóteses geradas a partir de evidências empíricas de três estudos foram expostas: 1) Interação sociocognitiva em ambiente virtual e desempenho acadêmico em universitários; 2) Análise comparativa da interação sociocognitiva em um espaço virtual e um tradicional; e 3) Características dos textos escritos em uma sala de aula virtual: das teorias ao caso e vice-versa. A necessidade de repensar a sala de aula como eixo do trabalho de pesquisa foi discutida.

Palavras-chave | psicologia educacional, aprendizagem mista, interação sóciocognitiva, universidade, metodologias de pesquisa

\section{Introducción}

En el análisis de la interacción mediada por entornos virtuales subyace una preocupación de corte metodológica. Esto es, al tiempo que reflexionamos acerca de aspectos prácticos y conceptuales, trabajando con docentes que utilizan espacios digitales con sus estudiantes, nos preguntamos cómo generar datos para repensar las interacciones que se dan en esos espacios. Las preguntas y posicionamientos iniciales que dan forma al trabajo se basan en una inquietud surgida a partir de la búsqueda de comprensión crítica de la construcción de datos en Psicología de la Educación: ¿cómo se construyen y qué se publica al respecto?

Por otro lado, la experiencia en talleres de formación de colegas docentes universitarios nos demostró que los datos concretos de interacción, relaciones y consecuencias posibles de esas acciones concretas permitían reflexionar de manera, por decirlo de algún modo, realista. Las generalizaciones dadas por algunos autores, a modo de receta de prácticas, resultaban difíciles de comprender en comparación con casos reales, descritos tal como los percibe gente real, trabajando, enseñando y aprendiendo en un contexto determinado. Estos talleres, además, daban a los docentes participantes espacios colectivos, es decir, escenarios óptimos para pensar, desde los propios modos de actuar en el mundo académico, en intervenciones adecuadas a sus contextos de trabajo. Asimismo, constituían para nosotros, como investigadores, un corpus de datos. Como consecuencia del trabajo así planteado, se obtuvo una construcción conjunta donde los participantes se constituyeron en co-investigadores.

Desde el inicio reconocemos, tanto cuando trabajamos en formación docente como cuando lo hacemos como investigadores, que un escenario no es transferible a otro escenario sino solo a través de sus reminiscencias. Pero sostenemos que el estudio de escenarios de enseñanza y aprendizaje abre caminos de reflexión sobre prácticas pedagógicas situadas. 
Nuestra investigación desarrolla el estudio de la interacción en entornos virtuales, específicamente en casos en los que el trabajo en el aula presencial se combina con el trabajo en el aula virtual. Los diseños blended learning, como se suele denominar a esta combinación de espacios de trabajo con el mismo grupo-clase, traen consigo una serie de desafíos tales como incorporar flexibilidad, estimular la intersección, facilitar los procesos de aprendizaje y generar un clima áulico afectivo (Boelens, De-Wever y Voet, 2017). Estos desafíos, además de disposición tecnológica adecuada, motivación al uso de tecnología en la docencia, formación docente suficiente (Borgobello, Sartori y Sanjurjo, 2018), entre otros, plantean la necesidad, para la Psicología de la Educación, de seguir estudiando y fortaleciendo la mirada sobre las interacciones concretas y situadas que se dan en las aulas virtuales y presenciales.

\section{Construcciones del objeto de investigación: caminos desde la teoría a los datos y viceversa}

En este campo del saber es frecuente encontrar diversos tipos de publicaciones. Una clasificación posible, sin intención de mutua exclusión o exhaustividad, incluiría: relatos de experiencias educativas concretas, modelos críticos basados en los cambios a que las tecnologías han dado lugar, "recetas" que ilustran cómo trabajar, y estudios basados en cuestionarios y experimentos. Estas publicaciones se basan en diálogos entre resultados, contexto y teoría (Figura 1), con distintas articulaciones entre estos tres aspectos, siempre presentes de modos más o menos directos, explícitos y articulados.

En la parte A de la Figura 1 se representa el modo en que suelen articularse datos de investigación y teoría en estas publicaciones, que por lo regular enfatizan en uno u otro componente. En la parte B de la Figura 1 se muestra lo que sucede en el trabajo con de datos concretos y teoría, en investigaciones reales. La simplificación y explicitación de las construcciones forman parte de nuestra tarea como investigadores, aunque reconozcamos que la realidad siempre es más compleja que cualquier abstracción que podamos hacer. 
Figura 1 | Relaciones entre teoría y datos en investigación. Autoría propia.
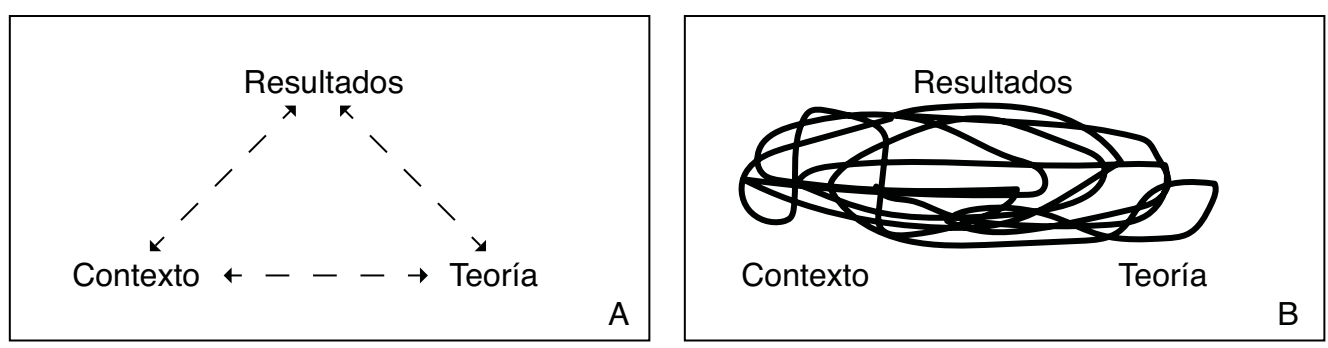

Entonces, teniendo en mente estas problemáticas, es dable preguntar: ¿qué relaciones es posible establecer entre teoría y datos en este campo específico de estudio? Sin lugar a duda, son muchas más que las que podrían pensarse en este texto y más diversas que las que plantean los manuales de metodología de investigación, donde son presentadas usualmente como "tipos ideales".

Según Archenti (2007), definir teoría cientifica representa una paradoja inicial ya que no es posible definirla sin pensar en teoría. Se podría decir que es el pensamiento de un autor o una corriente de pensamiento (por ejemplo, teoría marxista o psicoanálisis), una temática particular (como "teoría de la dependencia"), o aquella que refleja fuertemente contenidos metodológicos (una teoría general o una teoría de alcance medio) e, incluso, se puede equiparar teoría científica a paradigma, como visión o cosmovisión desde la cual se entiende y explica la realidad. Por nuestra parte, sostenemos que, a pesar de las diferencias, existe consenso en las diferentes perspectivas en cuanto al sentido relacional de la teoría, entendida como el conjunto de enunciados, o la relación de conceptos al interior de un sistema.

En este sentido, Archenti (2007) destaca que la teoría difiere en sus procesos lógicos, esto es, en los roles que desempeña en los procesos de investigación: de construcción, cuando se trata de procesos deductivos o inductivos; de evolución, cuando se trata de procesos por acumulación o ruptura. A riesgo de simplificar demasiado, en investigación, la realidad y la teoría implican contrastar (a partir de la teoría existente) o generar nueva teoría (construcción de nueva teoría). Así, la teoría, pensada desde diversos enfoques teórico-metodológicos, abre caminos conducentes a observaciones y devela relaciones entre fenómenos que se "escapan" a la experiencia inmediata. Si bien puede adoptar la forma de explicación o interpretación, devela algo "oculto" o naturalizado, esto es: "des-cubre". 
Figura 2 | Teoría y metodología. Autoría propia.
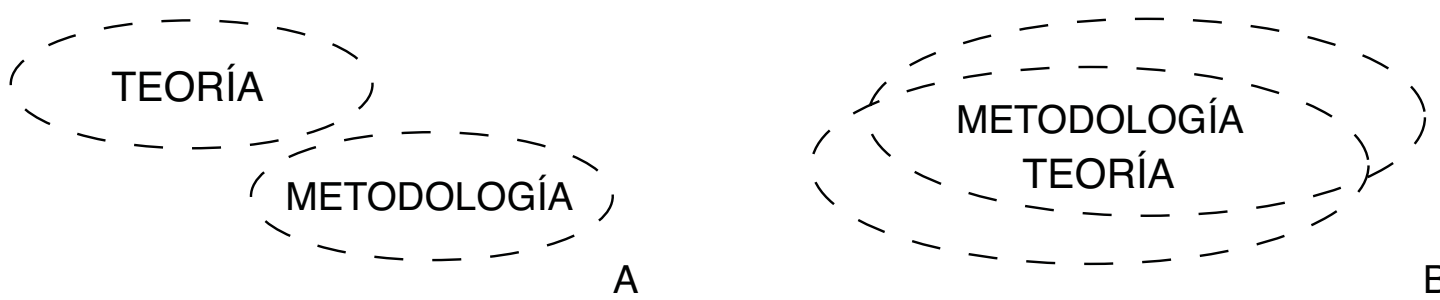

Ese desnaturalizar, descubrir o develar, implica un cómo en el que teoría y metodología se configuran en distintas posiciones lógicas, dependiendo del enfoque desde el cual se trabaje (Achilli, 2005). Desde una mirada clásica y ortodoxa, se trataría de aspectos e incluso de momentos escindibles (Figura 2, esquema A); desde una mirada compleja y dialéctica, serían inseparables (Figura 2, esquema B).

Enfatizando una posición teórico-metodológica, Menin y Temporetti (2005) postulan que los datos "puros" o "desnudos", al menos cuando se trabaja desde la Psicología, constituyen una "ficción positivista" ya que en su construcción intervienen los propios sujetos investigados. Además, en el ámbito universitario, suele resultar de escaso interés la metodología, prefiriéndose la teoría, algo con lo que el currículum universitario habitualmente colabora ya que suele dividir la formación en materias metodológicas o teóricas (Archenti, 2007), e incluso separarlas de las materias prácticas. Esto lleva a una dificultad al pensar la investigación: entender que habitualmente en ciencias sociales el método en cada investigación requiere de un diseño específico, de algún modo único, a partir de andamiajes conceptuales y datos.

Esta introducción fue pensada para entender adecuadamente lo que sigue: la postura según la cual los caminos que aquí presentamos son múltiples y únicos, incluso irrepetibles. Desde allí pensamos la investigación, desde allí construimos lo que podemos denominar, de acuerdo con lo dicho, "teoría de alcance medio". Esta teoría queda vinculada inescindiblemente a los cómo (materiales y métodos) y los qué (enfoques sucesivos hacia el objeto), en decisiones metodológicas asociadas a los desde dónde: desde las posturas teóricas y epistemológicas plasmadas a partir de escenarios irrepetibles que quedan objetivados en los estudios. 


\section{Presentación de la línea de trabajo}

Desde el enfoque complejo (Achilli, 2005) en que trabajamos, aceptamos como supuesto de partida que las decisiones metodológicas que vamos tomando no se centran únicamente en lecturas académicas y datos de investigación, sino que incluso nuestra biografía (fundamentalmente científica) está implicada en las elecciones que hacemos. Por tanto, los qué, cómo, cuándo y desde dónde investigamos superponen respuestas dadas en una construcción situada, conflictiva y teórico-metodológica, que llamamos proceso de investigación. En la Figura 3 pueden observarse una serie de conceptos, búsquedas y formas de abordaje del trabajo que venimos haciendo. Esta síntesis, sin embargo, puede considerarse como una "foto", es decir, como una imagen actual que, por capturarse en procesos dinámicos, irá modificándose en momentos posteriores del trabajo, así como ha cambiado respecto a "fotos" anteriores.

Figura 3 | Síntesis de la línea de investigación sobre blended learning. Autoría propia.

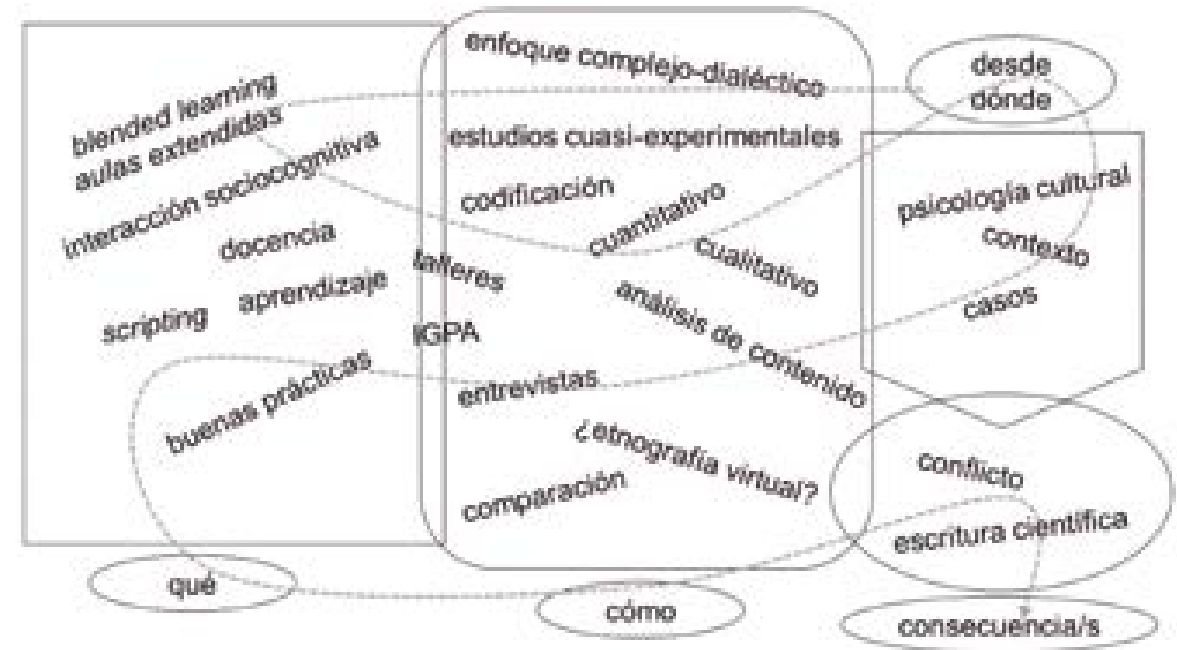

Esta línea de investigación (Figura 3), radicada en el Instituto Rosario de Investigaciones en Ciencias de la Educación (CONICET/UNR), se origina en el análisis de la interacción sociocognitiva en clases presenciales, y lleva la impronta del trabajo de observación en 
estudios tanto etnográficos como cuasiexperimentales (Borgobello y Peralta, 2011; Bogobello, Peralta y Roselli, 2013; Borgobello, Roselli y Peralta, 2010a, 2010b). Por ello, al incorporar el análisis de la interacción en aulas virtuales, se sostuvo el carácter observacional y empírico de origen. Esta impronta nos permite enfocar diferentes casos y problemáticas, comparando y reconociendo en cada uno singularidades y aspectos comunes relativos al objeto principal de indagación: el blended learning o la extensión de aulas tradicionales hacia (y desde) aulas virtuales (Borgobello, Raynaudo y Peralta, 2014; Borbobello, Sartori y Roselli, 2016).

En la actualidad, tomamos como ejes fundamentales la docencia, conceptos como scripting o modalidad de elaboración del guion (Borgobello, Sartori y Espinosa, 2018), y buenas prácticas de enseñanza dadas específicamente en cursos blended learning (e.g. Borgobello et al., 2016). Pensamos estos ejes como focos que nos permiten volver a pensar la clase y las formas básicas de enseñar (Sanjurjo, 2003) en tiempos de cambio, tras la "definitiva" incorporación de las $\mathrm{TIC}^{12}$ en la vida universitaria.

Para ello, utilizamos múltiples estrategias metodológicas en lo que consideramos, como ha sido dicho más arriba, un enfoque complejo-dialéctico (Achilli, 2005). Las entrevistas en profundidad nos permiten reconocer en las narraciones de los docentes en primera persona las historias singulares y las posturas teórico-epistemológicas desde las que se acercan al uso de entornos virtuales para el trabajo con los estudiantes (Borgobello et al., 2018). Las observaciones del registro observacional postfacto de aulas virtuales, en casos blended learning, dan a conocer la trama de interacción sociocognitiva en secuencias didácticas completas. Es decir, permiten miradas "Iongitudinales", a lo largo del tiempo que transcurre, que se traducen en una especie de etnografía virtual. Así, en esas observaciones nos detenemos en distintos tipos de datos, por ejemplo: construimos índices de las huellas que quedan en la plataforma (entradas, mensajes, performance académica); hacemos análisis cualitativo y cuantitativo de contenido de mensajes de foros (véase Estudio 1 del presente escrito); comparamos la interacción en clases presenciales y virtuales (aquí Estudio 2), y analizamos el conjunto de escritos de los docentes (consignas de trabajo, mensajes en foros, presentación de archivos, etc.), a través de diversos sistemas de codificación y análisis (como puede verse en el Estudio 3).

12 TIC es la sigla o acrónimo para Tecnologías de la Información y las Comunicaciones. 
En algunos momentos, al realizar esta tarea, se hace complejo separar los qué de los cómo, debido a que se encuentran entrelazados desde los proyectos mismos de investigación. Un ejemplo de ello son los talleres de formación para uso de Moodle (que no abordaremos aquí por razones de espacio) en los que, situándonos como docentes, reflexionamos en conjunto con los propios protagonistas y analizamos el contenido de estos como datos de investigación. De este modo, reconocemos las posiciones de docentes universitarios respecto al uso de TIC, al tiempo que dialogamos con ellos sobre la construcción de prácticas pedagógicas reflexivas, centradas en la extensión de las aulas a los espacios digitales en contextos que siempre son específicos.

Por las razones expuestas, entendemos que las prácticas pedagógicas, así como todas las prácticas humanas, se desarrollan en contextos culturales desde los que se construyen roles, creencias y actitudes (Bruner, 2005), que dan forma a nuestras mentes a partir de la cultura que es constituida por los instrumentos a través de los cuales nos construimos a nosotros mismos y actuamos (Bruner, 1997). Es desde allí desde dónde pensamos los casos, reconociendo a sus contextos como entornos constituidos y constituyentes de la trama de interacción que tiene lugar.

Estas miradas investigativas, respetuosas de las posiciones de los docentes y de los escenarios en los que tienen lugar las prácticas pedagógicas que estudiamos, atraen la crítica dentro del contexto científico de la Psicología Educativa: se convierten en difíciles de publicar. Los referatos de las revistas suelen hacer críticas a los escritos desde miradas convencionales, ya sean cualitativas o cuantitativas; desde las "exigencias" impuestas por paradigmas basados habitualmente en cualidades "sin números" o, en su polo "opuesto", en análisis cuantitativos en cuyo diseño se maneja "más control" que el que ejercemos en nuestras investigaciones. En este sentido es que entendemos que Bruner (1997) reclama el fin de un enfoque tipo o-lo-unolo-otro. La cultura se encuentra en proceso de constante creación y recreación por medio de la interpretación y negociación de significados. El conocimiento científico es una construcción sociocultural que implica negociaciones de significados, algunas de ellas más difíciles que otras, como otras construcciones culturales de las que formamos parte. 


\section{Conclusiones e hipótesis generadas a partir de evidencia empírica}

En este punto asumimos el desafío de presentar conclusiones teóricas antes de mostrar "los datos", algo que haremos a posteriori. Podemos decir que en estas investigaciones generamos teoría de alcance medio (en sentido de Archenti, 2007), fuertemente vinculada a los aspectos teórico-metodológicos que dieron lugar a decisiones progresivas. Cabe reconocer que pueden tomarse estos aportes también como hipótesis propias de estudios exploratorios, como puntos de llegada para nuevas partidas investigativas (Ynoub, 2007) que tienen lugar luego de las indagaciones preliminares, pero no pretenden ser, como es de esperar en los procedimientos hipotético-deductivos, afirmaciones a ser confirmadas por una investigación.

La mayor parte de los trabajos presentados se centran en aulas concretas como unidades de estudio. En sentido amplio, las experiencias investigativas pueden encontrarse como sugerencias para el trabajo con blended learning en aulas universitarias, pero no como sugerencias a nivel institucional. Así, reconocemos, como plantea Camillioni (2016), que si bien existen múltiples relaciones que entrelazan los niveles que comprende la educación formal (como la teoría se relaciona con la práctica), la dimensión institucional y la enseñanza requieren decisiones cotidianas que toman personas diferentes. En el mismo sentido de nuestra analogía entre teoría y práctica, los aspectos teóricos que destacamos como productos de los estudios realizados se convierten en consideraciones posibles, para ser tenidas en cuenta por parte de docentes que trabajan con esta modalidad pedagógica en sus propios contextos de enseñanza y aprendizaje.

Cada una de las ocho afirmaciones conceptuales, que componen el listado que presentamos a continuación, están basadas en datos empíricos construidos a partir de diferentes estudios que expondremos luego. Cada una de ellas conlleva sugerencias construidas a partir estudios de esta línea de trabajo:

1. En cuanto al trabajo en el entorno virtual, la gestión del tiempo se muestra como superadora de la linealidad sincrónica que impondría el trabajo presencial. En el espacio virtual se multiplican caminos, se diversifica, se permite profundizar conceptos, volver sobre temas ya trabajados con anterioridad (Bogobello y Roselli, 2016; Borgobello et al., 2016; Borgobello et al., 2017b). Sin embargo, en contraposición con lo que sucede en las clases 
presenciales, los estudiantes encuentran dificultades para lograr acuerdos y manifiestan que los compañeros muestran escaso compromiso con el trabajo en el aula virtual (Borgobello et al., 2017a). La gestión de la tarea podría combinar de manera óptima los espacios, dejando, por ejemplo, la etapa de cierre para el aula presencial, exigiendo trabajo previo colaborativo o cooperativo en el aula virtual.

2. Los estudiantes con mejor performance general son más participativos y tienen un discurso de mayor presencia social (saludos, diálogos) y organizativa (mencionan y siguen la tarea) (Borgobello y Roselli, 2016). Fomentar un diálogo integral, que reúna la presentación del contenido conceptual vinculado a la tarea y la presencia social, podría llevar a mejorar la performance académica.

3. El ambiente presencial muestra las ventajas de la inmediatez. Los estudiantes señalan que al compartir el espacio cara-a-cara pueden expresar dudas y generar acuerdos al reconocer la gestualidad de los interlocutores con mayor facilidad que en el entorno virtual. Sin embargo, en actividades grupales del aula tradicional se distraen más. Aquí, cabe mencionar que, en general, los estudiantes encuentran dificultades para señalar las desventajas de lo más conocido, es decir, de la clase presencial (Borgobello et al., 2017a). Identificar tipos de tarea y formas de acuerdo distintas, acordes con el espacio de trabajo, beneficiaría el desarrollo de la tarea y, probablemente, evitaría frustraciones vinculadas con el proceso.

4. Cuando se trabaja blended learning, en el aula virtual el discurso es más coherente y ordenado (Borgobello et al., 2016) que en el aula tradicional. Por ello resulta recomendable iniciar discusiones en el aula virtual para continuarlas en el entorno presencial.

5. El blended learning permite combinar las ventajas de la comunicación oral y la escrita, propiciando la interacción sociocognitiva en el aprendizaje y facilitando así la construcción colaborativa de conocimiento (Borgobello et al., 2016). Se trata de enriquecer la comunicación en ambientes con alta disposición tecnológica, que solo serán fructíferos cuando los propios docentes propicien una comunicación productiva (Maggio, 2016). Adicionalmente, la colaboración con otros beneficiaría a quienes tienen distintos rendimientos previos. Sin duda, depende de los propios docentes fomentar este tipo de trabajo. 
Volumen 3 • Número 1 • enero - junio 2020 • Págs. 129 - 158 •

ISSN: 2389-8798 impreso / ISSN 2539-1445 (En línea) / Tunja, Boyacá (Colombia)

6. El tipo de intervenciones docentes son más heterogéneas en clases tradicionales, en comparación con las que pueden apreciarse en el entorno virtual (Borgobello et al., 2016). La síntesis y la brevedad son idóneas para las presentaciones escritas propias de los entornos virtuales.

7. Los estudiantes que más utilizan la plataforma creen que sus docentes explican con claridad en las clases presenciales, es decir, parecen comprender mejor los conceptos trabajados presencialmente (Borgobello y Roselli, 2016). Diversificar el tipo de tareas propuestas en el aula virtual puede motivar a trabajar de distintas formas contenidos curriculares, beneficiando así el "entrar en contacto" con términos propios de la disciplina enseñada y facilitando la comprensión conceptual.

8. Los textos que escribe un docente en el espacio virtual pueden clasificarse como textos de apertura organizativos, textos-link y textos de tutoría (Borgobello et al., 2017b, 2018). Los textos de apertura explican aspectos organizativos generales de las tareas y de los cursos y se dirigen al grupo-clase. Los textos-link son generalmente títulos de recursos utilizados, como literatura para las clases, o links internos y externos al entorno virtual. Es de suponer que, en estos últimos textos-link, las consignas o explicaciones acerca del recurso ya han sido transmitidas en clases presenciales, pues generalmente aparecen mencionados como una palabra, por ejemplo, el apellido de un autor. Finalmente, los textos de tutoría muestran el carácter interactivo que propician y promueven este tipo de espacios digitales. En ellos, la direccionalidad del diálogo se da a grupos pequeños, o un estudiante en particular, y suelen presentarse en foros, en los que se personaliza el trabajo. Se sugiere evitar el segundo tipo de textos-link que carece de información suficiente en el espacio virtual y resulta incomprensibles para quien, por ejemplo, no presenció la clase tradicional. Los textos que acompañan a los archivos o links debieran contener la información básica necesaria que le permita al estudiante situarlo en el contexto de la materia en la que se encuentra.

Estas sugerencias y recomendaciones relacionadas con el uso de entornos virtuales en casos blended learning están basadas en las experiencias investigativas que exponemos a continuación. Lejos está de nuestra intención que se conviertan en recetas encorsetadas ya que cada docente, en su contexto institucional, tendrá que concretar su trabajo pedagógico 
reflexionando en torno a los contenidos y estudiantes con los que esté trabajando. Sin embargo, como lo expusimos, sostenemos que este tipo de estudios favorecen la reflexión en contexto que estamos planteando como necesaria para la enseñanza universitaria.

\section{Caminos recorridos desde los datos empíricos a las afirmaciones teóricas}

En los apartados siguientes, se describen someramente tres estudios realizados en la línea de investigación que presentamos: Estudio 1: Interacción sociocognitiva en un entorno virtual y rendimiento académico de estudiantes universitarios; Estudio 2: Análisis comparativo de la interacción sociocognitiva en un espacio virtual y otro tradicional; y Estudio 3: Desde las teorías al caso y viceversa: características de textos escritos en un aula virtual. Los primeros dos se encuentran publicados, de modo que haremos solo una reconstrucción que permita reconocer la construcción empírica que dio lugar a las afirmaciones que se encuentran más arriba. El tercero de los estudios es un estudio en curso, enviado para publicación, por lo que nos vemos en la necesidad de explayar más las explicaciones acerca de las decisiones teóricometodológicas que tuvieron lugar en esa indagación.

\section{Estudio 1. Interacción sociocognitiva en un entorno virtual y rendimiento académico de estudiantes universitarios}

Este estudio estuvo centrado en dos objetivos primordiales: la construcción de perfiles de estudiantes usuarios de la plataforma, en cuatro cursos dados blended learning, y el análisis de las características de los mensajes escritos en foros, por cinco sujetos con alta y baja performance académica general (En adelante: Índice General de Performance Académica (IGPA). (Véanse mayores detalles en: Borgobello y Roselli, 2016).

Para este estudio, trabajamos con datos pertenecientes a 127 estudiantes de primer año de una carrera de ciencias sociales. Aplicamos un cuestionario en el que se indagaba por las percepciones de los estudiantes acerca del curso, las fuentes de estudio para los exámenes, los hábitos en relación con el uso de internet y la computadora, sus opiniones sobre Moodle como entorno virtual, y sus preferencias respecto de actividades y recursos.

Adicionalmente, en relación con el segundo objetivo planteado, se transcribió un total de 107 mensajes escritos en los foros propuestos por los docentes, a lo largo del curso, 
pertenecientes a los cinco estudiantes con más alto IGPA y los cinco estudiantes con más bajo IGPA. Asimismo, para la construcción de IGPA, se registraron las calificaciones obtenidas por los estudiantes en los exámenes regulares de la asignatura, la cantidad de mensajes escritos en foros y las entradas realizadas en la exploración del espacio (el total de clics hechos en el espacio).

A partir del análisis de correspondencias múltiples, con clasificación de coordenadas factoriales y selección de variables activas e ilustrativas (Moscoloni, 2005), se distinguieron tres clases caracterizadas por uso bajo, medio y alto.

La Clase 1 representa al $40 \%$ de los participantes $(n=51)$ que se caracterizaron por tener los índices de entradas e índices de mensajes más bajos. A estos estudiantes, les agradó escasamente utilizar la plataforma y sostuvieron que, en general, utilizan poco la computadora con fines académicos. Consideraron que el recurso mejor diseñado por los docentes fueron los foros.

La Clase 2 reunió al grupo más amplio de estudiantes, representando casi el $49 \%$ de la muestra $(n=62)$. Si bien manifestaron que les agradó bastante o mucho utilizar la plataforma, sus índices de mensajes y entradas fueron medios. Declararon utilizar mucho la plataforma para estudiar para el examen. Su recurso de preferencia fue el cuestionario.

La Clase 3 fue la más pequeña, representando el $11 \%$ del grupo $(n=14)$. Estos estudiantes se caracterizaron por utilizar ampliamente la plataforma. Los estudiantes de esta clase puntuaron con la categoría más alta a las explicaciones dadas por los docentes, considerándolas como muy claras. No mostraron preferencia como grupo por algún recurso o actividad en particular. 
Figura $4 \mid$ Proyección de los casos identificados por su número de clase en el primer plano factorial.

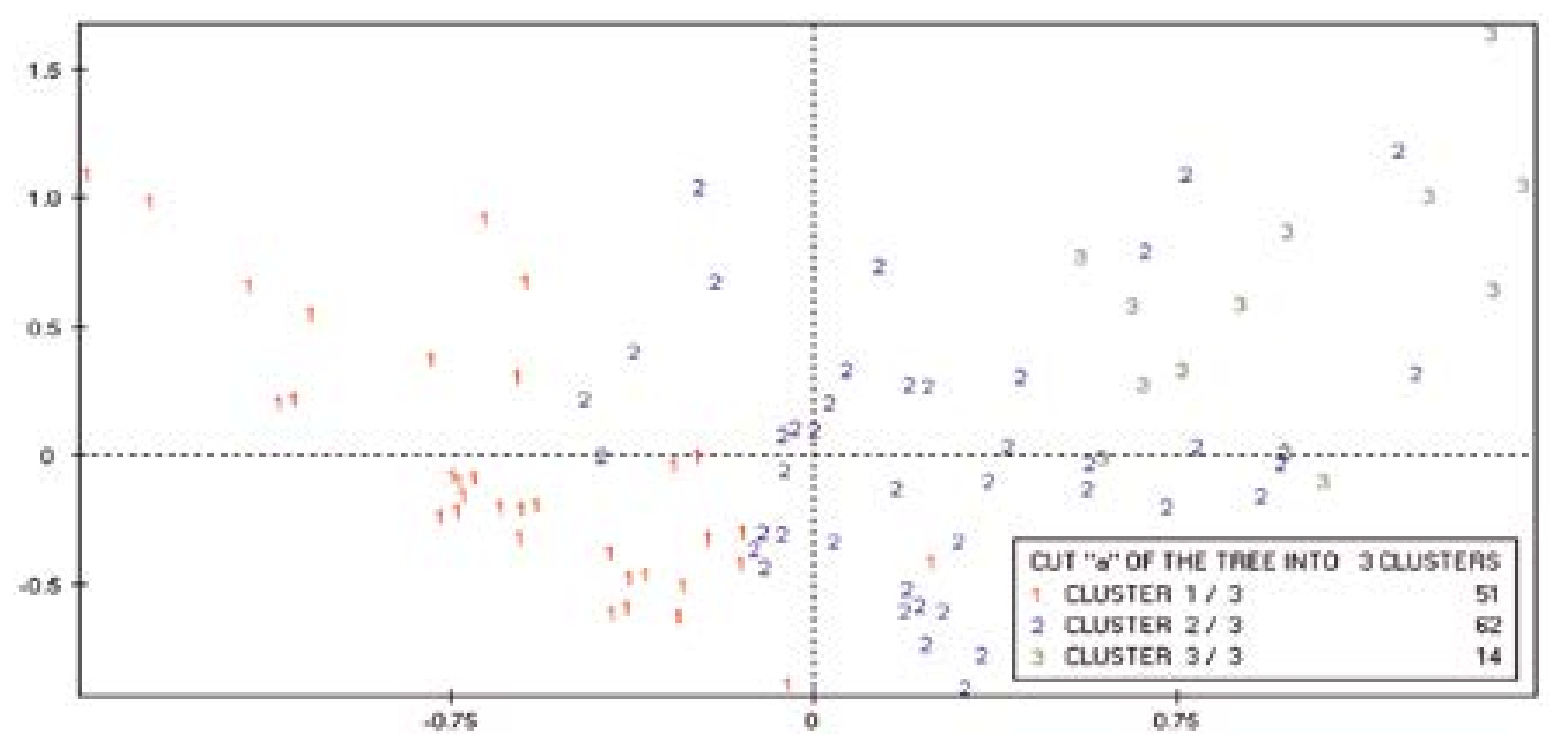

Fuente: Borgobello y Roselli (2016, p.369).

En cuanto al análisis de contenido cuantitativo (Piovani, 2007) realizado sobre los mensajes escritos en los foros del curso por parte de los estudiantes con más alto y más bajo IGPA, cada mensaje fue tomado como unidad de análisis, consignándose si el mismo podía ser clasificado en cada una de las variables presentes en la Tabla 1. El contenido de cada mensaje fue clasificado, siguiendo a Roselli, Dominino y Peralta (2010), por la presencia de contenido socioafectivo (saludos, emoticones, es decir, presencia social), organizativo (mención a la consigna o a la tarea) y cognitivo-académico (definiciones conceptuales, información del tema trabajado, etc.). Asimismo, se registró si el mensaje se encontraba anidado (se escribía como respuesta a un compañero o era respuesta a una publicación de un compañero), si utilizaba preguntas, si era elaboración o copia de otro texto, si se encontraba en un foro obligatorio u optativo, y si usaba primera persona en la redacción. 
Volumen 3 • Número 1 • enero - junio 2020 • Págs. 129 - 158 •

ISSN: 2389-8798 impreso / ISSN 2539-1445 (En línea) / Tunja, Boyacá (Colombia)

Tabla $1 \mid$ Características de los mensajes escritos por los estudiantes con más alto y bajo IGPA

\begin{tabular}{|c|c|c|c|c|c|c|c|c|c|}
\hline & & \multicolumn{4}{|c|}{$\begin{array}{c}\text { Mensaje de los cinco estudiantes con } \\
\text { más alto IGPA }\end{array}$} & \multicolumn{4}{|c|}{$\begin{array}{c}\text { Mensajes de los cinco estudiantes } \\
\text { con más bajo IGPA }\end{array}$} \\
\hline & & Mínimo & Máximo & $f$ & $\%$ & Mínimo & Máximo & $f$ & $\%$ \\
\hline \multirow{12}{*}{$\begin{array}{l}\text { Contenido del } \\
\text { mensaje }\end{array}$} & $\begin{array}{l}\text { Sí cognitivo- } \\
\text { académico }\end{array}$ & 9 & 18 & 73 & 79 & 2 & 3 & 14 & 100 \\
\hline & $\begin{array}{l}\text { No cognitivo- } \\
\text { académico }\end{array}$ & 1 & 9 & 20 & 21 & - & - & - & - \\
\hline & $\begin{array}{l}\text { Sí socio- } \\
\text { afectivo }\end{array}$ & 4 & 16 & 48 & 52 & - & 1 & 2 & 14 \\
\hline & $\begin{array}{l}\text { No socio- } \\
\text { afectivo }\end{array}$ & 6 & 11 & 45 & 48 & 2 & 3 & 12 & 86 \\
\hline & Sí organizativo & 1 & 14 & 33 & 36 & - & - & - & - \\
\hline & $\begin{array}{l}\text { No } \\
\text { organizativo }\end{array}$ & 9 & 13 & 60 & 64 & 2 & 3 & 14 & 100 \\
\hline & Con pregunta & 1 & 5 & 13 & 14 & - & - & - & - \\
\hline & Sin pregunta & 11 & 22 & 80 & 86 & 2 & 3 & 14 & 100 \\
\hline & $\begin{array}{l}\text { Con uso } \\
\text { de primera } \\
\text { persona }\end{array}$ & 2 & 9 & 26 & 28 & - & 1 & 1 & 7 \\
\hline & $\begin{array}{l}\text { Sin uso de } \\
\text { primera } \\
\text { persona }\end{array}$ & 7 & 19 & 67 & 72 & 2 & 3 & 13 & 93 \\
\hline & Copia textual & 1 & 25 & 11 & 12 & - & 2 & 3 & 21 \\
\hline & $\begin{array}{l}\text { Con } \\
\text { elaboración }\end{array}$ & 2 & 20 & 82 & 88 & 1 & 3 & 11 & 79 \\
\hline \multirow{2}{*}{$\begin{array}{l}\text { Interacción } \\
\text { explícita ente } \\
\text { estudiantes }\end{array}$} & Sí anidado & 8 & 16 & 64 & 69 & - & 2 & 4 & 29 \\
\hline & No anidado & 4 & 11 & 29 & 31 & 1 & 3 & 10 & 71 \\
\hline \multirow{2}{*}{ Tipo de foro } & Obligatorio & 10 & 23 & 76 & 82 & 2 & 3 & 14 & 100 \\
\hline & Optativo & 1 & 5 & 17 & 18 & - & - & - & - \\
\hline
\end{tabular}


Mensaje de los cinco estudiantes con Mensajes de los cinco estudiantes más alto IGPA con más bajo IGPA

\begin{tabular}{lcccccccc}
\hline & Mínimo & Máximo & $\mathrm{f}$ & $\%$ & Mínimo & Máximo & $\mathrm{f}$ & $\%$ \\
\hline $\begin{array}{l}\text { Total de } \\
\text { mensajes }\end{array}$ & 12 & 27 & 93 & 100 & 2 & 3 & 14 & 100 \\
\hline
\end{tabular}

Nota 1: $N=107$ mensajes escritos en foros de la plataforma Moodle por los cinco estudiantes con más bajo y más alto IGPA (Índice General de Performance Académica).

Nota 2. Fuente: Borgobello y Roselli (2016, p.370).

Más allá de la diferencia evidente y esperable en cuanto a la cantidad de mensajes escritos por el grupo de más alto y más bajo IGPA, los resultados mostraron diferencias notables en el contenido de los mensajes, especialmente en lo que no es estrictamente cognitivo, es decir, en cuanto al contenido socio-afectivo y organizativo. Asimismo, la presencia de anidación en las respuestas, destacando el diálogo entre compañeros de curso, fue significativamente superior en los estudiantes de alto IGPA y fueron los únicos que escribieron en foros optativos.

\section{Estudio 2. Análisis comparativo de la interacción sociocognitiva en un espacio virtual y otro tradicional}

Este estudio tuvo como objetivo principal comparar las características de la interacción sociocognitiva de un mismo grupo de estudiantes, trabajando con el mismo docente, en una clase presencial y otra virtual (Borgobello et al., 2016). Adicionalmente, a través de un cuestionario con preguntas abiertas, se indagó acerca de las ventajas y desventajas percibidas por los estudiantes en ambos espacios (presencial y virtual) respecto de la tarea requerida (Borgobello et al., 2017a).

Para ello, se diseñaron dos tareas ad hoc con un grupo de 12 estudiantes que trabajaban habitualmente con modalidad blended learning. En coordinación con el docente a cargo del curso, se buscó que las tareas fuesen similares, es decir, se organizaran a partir de consignas de trabajos equiparables. El trabajo pedagógico se dividió en tres momentos (Figura 5): el inicial y el final con el grupo-clase en su conjunto; y el intermedio se trabajó en grupos pequeños. Se grabaron en audio y se transcribieron el primer y último momento de la tarea dada en la clase presencial, con el grupo-clase en su conjunto interactuando, y se transcribieron todos los mensajes escritos en el aula virtual. 
Figura 5 | Diseño del estudio.

\begin{tabular}{|c|c|c|}
\hline Momento 1 & Momento 2 & Momento 3 \\
\hline $\begin{array}{l}\text { Trabajo grupal } \\
\text { conjunto } \\
\text { Presentación } \\
\text { de contenidos }\end{array}$ & $\begin{array}{l}\text { Trabajo en } \\
\text { grupos } \\
\text { pequeños } \\
\text { Construcción } \\
\text { de ejemplos }\end{array}$ & $\begin{array}{l}\text { Retrabajo } \\
\text { grupal } \\
\text { conjunto } \\
\text { Exposición de } \\
\text { un ejemplo por } \\
\text { grupo y } \\
\text { retrabajo con } \\
\text { el docente de } \\
\text { los conceptos } \\
\text { y ejemplos }\end{array}$ \\
\hline
\end{tabular}

Fuente: Elaboración propia.

Luego se utilizaron dos modelos de codificación de la interacción: uno diseñado para las clases presenciales y otro pensado para las interacciones mediadas (Borgobello et al., 2010a; Garrison, Anderson, y Archer, 2000).

Como ya se ha dicho, el modelo de Garrison et al. (2000) fue inicialmente pensado para el análisis del diálogo en entornos virtuales. Este sistema de codificación, sostienen los autores, contiene categorías válidas para analizar cualquier interacción dada en una comunidad de indagación.

Los tres elementos básicos del modelo son la presencia cognitiva, la docente y la social. La denominada presencia cognitiva se refiere a la construcción activa de significados que se realizan en una comunicación mediada. Se trata del elemento clave para la construcción del pensamiento crítico, presentado habitualmente como meta de la educación superior. La presencia social es definida como la capacidad para proyectar sus propias características personales en la comunidad virtual, de manera que las personas logran presentarse como "gente real" ante los demás participantes. Esta forma de presencia contribuye a que la experiencia educativa genere, por ejemplo, un grupo disfrutable en el transcurso del tiempo 
compartido en un curso. La presencia docente es responsabilidad primaria del profesor, pero no exclusiva, es decir, puede ser ejercida por cualquiera de los participantes. Sus funciones se relacionan con el diseño de la experiencia educativa (selección, organización y presentación de los contenidos) y el desarrollo de las actividades de aprendizaje y evaluación. Para los autores, la presencia docente puede entenderse como un medio para un fin, porque implica apoyar y mejorar la presencia cognitiva y social con el objetivo de lograr resultados educativos (Garrison et al., 2000).

El segundo modelo de codificación utilizado fue construido como planilla de observación de clases y pensado para el análisis de la interacción en clases presenciales universitarias (Borgobello et al., 2010a). En este modelo de observación se diferencian las intervenciones de estudiantes y de docentes. En la observación del docente, se codificaron los fragmentos en: preguntas no respondidas por los alumnos (PSR) y aquellas que obtuvieron respuesta por parte del docente (PCR); sugerencias de técnicas o procedimientos para estudiar (STP); sugerencias y menciones de bibliografía (SB); expresiones de motivación (EM); aclaraciones de términos conceptuales (AT); relaciones conceptuales con temas diferentes a los que se dan en la clase analizada (RCT); historizaciones de conceptos (HC); uso de metáforas explicativas, comparaciones y/o ejemplos de conceptos (MCE); pedidos de disciplina (PD); y aspectos organizativos relacionados con alguna tarea o con la clase $(\mathrm{AO})$. En relación con la observación de los estudiantes, se codificaron: pedidos de aclaración dirigidos al docente (PA); solicitudes de repetición de algo dicho (PR), e intervenciones conceptuales (IC).

Tabla 2 |Análisis de la interacción a partir de dos modelos de codificación

\begin{tabular}{|c|c|c|c|c|c|c|c|c|c|}
\hline & & \multicolumn{4}{|c|}{ Presencial } & \multicolumn{4}{|c|}{ Virtual } \\
\hline & & $P C$ & PS & PD & Total & PC & PS & PD & Total \\
\hline \multirow{2}{*}{ PSR } & $f$ & 1 & 2 & 54 & 57 & & & & \\
\hline & $\%$ & 0,2 & 0,4 & 9,7 & 10,2 & & & & \\
\hline \multirow[t]{2}{*}{ PCR } & $f$ & 2 & 12 & 55 & 69 & & & & \\
\hline & $\%$ & 0,4 & 2,2 & 9,9 & 12,4 & & & & \\
\hline
\end{tabular}


Volumen 3 • Número 1 • enero - junio 2020 • Págs. 129 - 158 •

ISSN: 2389-8798 impreso / ISSN 2539-1445 (En línea) / Tunja, Boyacá (Colombia)

\begin{tabular}{|c|c|c|c|c|c|c|c|c|c|}
\hline & & \multicolumn{4}{|c|}{ Presencial } & \multicolumn{4}{|c|}{ Virtual } \\
\hline & & PC & PS & PD & Total & PC & PS & PD & Total \\
\hline \multirow{2}{*}{ PD } & f & & & 2 & 2 & & & & \\
\hline & $\%$ & & & 0,4 & 0,4 & & & & \\
\hline \multirow{2}{*}{$\mathrm{AO}$} & $f$ & 4 & 3 & 100 & 107 & & & 7 & 7 \\
\hline & $\%$ & 0,7 & 0,5 & 18,0 & 19,2 & & & 30,4 & 30,4 \\
\hline \multirow{2}{*}{ SB } & $f$ & 17 & & 13 & 30 & 2 & & 1 & 3 \\
\hline & $\%$ & 3,1 & & 2,3 & 5,4 & 8,7 & & 4,3 & 13,0 \\
\hline \multirow{2}{*}{ AT } & $f$ & 77 & & 4 & 81 & 5 & & & 5 \\
\hline & $\%$ & 13,8 & & 0,7 & 14,5 & 21,7 & & & 21,7 \\
\hline \multirow{2}{*}{ RCOT } & $f$ & 4 & & 1 & 5 & & & & \\
\hline & $\%$ & 0,7 & & 0,2 & 0,9 & & & & \\
\hline \multirow{2}{*}{$\mathrm{HC}$} & $f$ & 9 & & & 9 & & & & \\
\hline & $\%$ & 1,6 & & & 1,6 & & & & \\
\hline \multirow{2}{*}{ ME } & $f$ & 15 & 1 & 1 & 17 & & & & \\
\hline & $\%$ & 2,7 & 0,2 & 0,2 & 3,1 & & & & \\
\hline \multirow{2}{*}{ STP } & $f$ & & & 9 & 9 & & & 3 & 3 \\
\hline & $\%$ & & & 1,6 & 1,6 & & & 13 & 13 \\
\hline \multirow{2}{*}{ EM } & $f$ & 1 & 10 & 38 & 49 & & & & \\
\hline & $\%$ & 0,2 & 1,8 & 6,8 & 8,8 & & & & \\
\hline \multirow{2}{*}{ RANC } & $f$ & & 1 & 1 & 2 & & & & \\
\hline & $\%$ & & 0,2 & 0,2 & 0,4 & & & & \\
\hline \multirow{2}{*}{ AJD } & $f$ & & 9 & & 9 & & 2 & & 2 \\
\hline & $\%$ & & 1,6 & & 1,6 & & 8,7 & & 8,7 \\
\hline \multirow[t]{2}{*}{ PA } & $f$ & & 1 & 8 & 9 & & & & \\
\hline & $\%$ & & 0,2 & 1,4 & 1,6 & & & & \\
\hline \multirow{2}{*}{ PR } & $f$ & & & 2 & 2 & & & & \\
\hline & $\%$ & & & 0,4 & 0,4 & & & & \\
\hline \multirow{2}{*}{ IC } & $f$ & 29 & 2 & 3 & 34 & 3 & & & 3 \\
\hline & $\%$ & 5,2 & 0,4 & 0,5 & 6,1 & 13 & & & 13 \\
\hline
\end{tabular}




\begin{tabular}{|c|c|c|c|c|c|c|c|c|c|}
\hline & & \multicolumn{4}{|c|}{ Presencial } & \multicolumn{4}{|c|}{ Virtual } \\
\hline & & PC & PS & PD & Total & PC & PS & PD & Total \\
\hline \multirow{2}{*}{ RDNC } & $f$ & 4 & 22 & 35 & 61 & & & & \\
\hline & $\%$ & 0,7 & 3,9 & 6,3 & 11 & & & & \\
\hline \multirow{2}{*}{ AJE } & $f$ & & 4 & 1 & 5 & & & & \\
\hline & $\%$ & & 0,7 & 0,2 & 0,9 & & & & \\
\hline \multirow{2}{*}{ Total } & $f$ & 163 & 67 & 327 & 557 & 10 & 2 & 11 & 23 \\
\hline & $\%$ & 29,3 & 12 & 58,7 & 100 & 43,5 & 8,7 & 47,8 & 100 \\
\hline
\end{tabular}

Nota 1. Presencia Docente (PD); Presencia Cognitiva (PC) y Presencia Social (PS)

Nota 2: Intervenciones docentes: Pregunta Sin Respuesta (PSR); Pregunta Con Respuesta (PCR); Pedidos de Silencio o Disciplina (PD); Aspectos Organizativos (AO); Sugerencia o mención de Bibliografía (SB); Aclaración de Términos o conceptos (AT); Relaciones Conceptuales con Otros Temas (RCOT); Historizaciones de Conceptos (HC); Metáforas explicativas, Comparaciones o ejemplos; Metáforas Explicativas, comparaciones o ejemplos (ME); Sugerencias de Técnicas de estudio o Procedimientos (STP); Expresiones de Motivación (EM); Respuesta a Alumno No Conceptual (RANC); otra afirmación ajena a la clase (AJD). Intervenciones de los estudiantes: Pedidos de Aclaración (PA); Pedidos de Repetición (PR); Intervenciones Conceptuales (IC); Respuesta al Docente (No Conceptual) (RDNC); otra afirmación ajena a la clase (AJE).

Nota 3. Fuente: Borgobello et al. (2016, pp.104-105)

Como puede apreciarse en la Tabla 2, los resultados del análisis de la interacción mostraron mayor número de fragmentos y diversidad, en la codificación de la clase presencial comparada con la virtual. Asimismo, las intervenciones de los estudiantes fueron particularmente escasas en el entorno virtual, remitiéndose únicamente a la concreción de la tarea solicitada.

Como se ha dicho, también se indagó, a través de un cuestionario, por las ventajas y desventajas del trabajo realizado en ambos espacios. Los estudiantes destacaron la posibilidad de volver sobre los contenidos en el entorno virtual, manejando sus propios tiempos. En cuanto a las desventajas acerca de la actividad realizada en la plataforma, mencionaron dificultades en la coordinación y en el "ponerse de acuerdo". Asimismo, señalaron la ausencia de inmediatez, remarcando, por ejemplo, el no poder preguntar en el momento en que surgía alguna duda. Por otro lado, manifestaron que el compromiso con la tarea parece menor cuando falta la presencia inmediata del compañero. 
En relación con la actividad realizada en el aula tradicional, los estudiantes destacaron la inmediatez como ventaja, debido a diversos aspectos: el poder trabajar las dudas en el momento en que surgen, ver las reacciones faciales de los compañeros para lograr acuerdos rápidos y tácitos, el acceder al debate y el entendimiento en la continuidad del diálogo. Cabe destacar que algunos estudiantes señalaron como desventaja, de la actividad realizada en forma presencial, el que suelan distraerse con temas ajenos a la tarea, cuando trabajan en grupos pequeños. Sin embargo, en general, encontraron dificultad para señalar desventajas del ambiente tradicional.

\section{Estudio 3. Desde las teorías al caso y viceversa: características de textos escritos en un aula virtual}

El tercer estudio presentado constituye un avance de un trabajo en curso (Borgobello et al., 2017b). Se basa en el análisis de la modalidad de elaboración del guion -o scripting (en su denominación inglesa), por parte de un docente en un aula virtual a lo largo de un curso anual. En este caso, solo se tomaron todos y cada uno de los textos publicados por el docente y visibles para todo el grupo-clase en el entorno virtual, es decir, se descartaron los mensajes enviados por mensajería privada.

Cada mensaje fue categorizado siguiendo tres modelos teóricos diferentes:

1. Tipos de presencia: docente, cognitiva y social (Garrison et al., 2000)

2. Dimensiones de la tutoría docente (basado en Onrubia y Engel, 2012)

3. Formas de enseñar (basado en Sanjurjo, 2003)

\section{Tipos de presencia.}

El primer modelo de análisis contiene las categorías de Garrison et al., (2000) explicadas en relación con el Estudio 2: presencia cognitiva, docente y social (ver síntesis en la Figura 6). 
Figura 6| Modelo traducido de Garrison et al., (2000).

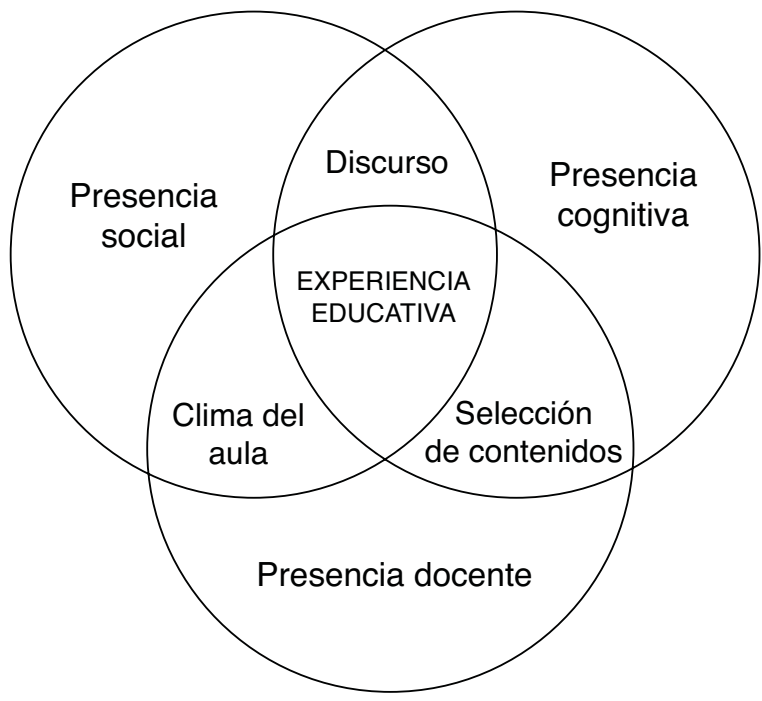

Fuente: Borgobello et al., (2016, p.361)

\section{Dimensiones de la tutoría docente.}

Las múltiples dimensiones de la tutoría docente (ver Figura 7) fueron analizadas a partir del esquema planteado por Onrubia y Engel (2012). Los textos escritos, como por ejemplo las consignas publicadas y los mensajes presentes en los foros, fueron categorizados en las cuatro dimensiones propuestas por los autores para el análisis del scripting docente. Las dimensiones relacionadas con la actividad fueron: elaboración de las tareas; planificación, organización y proceso de trabajo; gestión del curso; uso de recursos tecnológicos, y atmósfera social. De acuerdo con el momento en que se escribía el texto, se consignaba como antes (al dar inicio), durante o después de la tarea (al dar cierre a alguna actividad) con la que se relacionaba. En cuanto a quién o a quiénes estaba dirigido el escrito: podía ser un estudiante en particular, un grupo pequeño o el grupo-clase en su conjunto. De acuerdo con el origen del escrito, cada uno fue consignado como: espontáneo o requerido, esto es, escrito en respuesta a un mensaje de un estudiante. 
Figura 7| Modelo adaptado y traducido de Onrubia y Engel (2012, p.170).

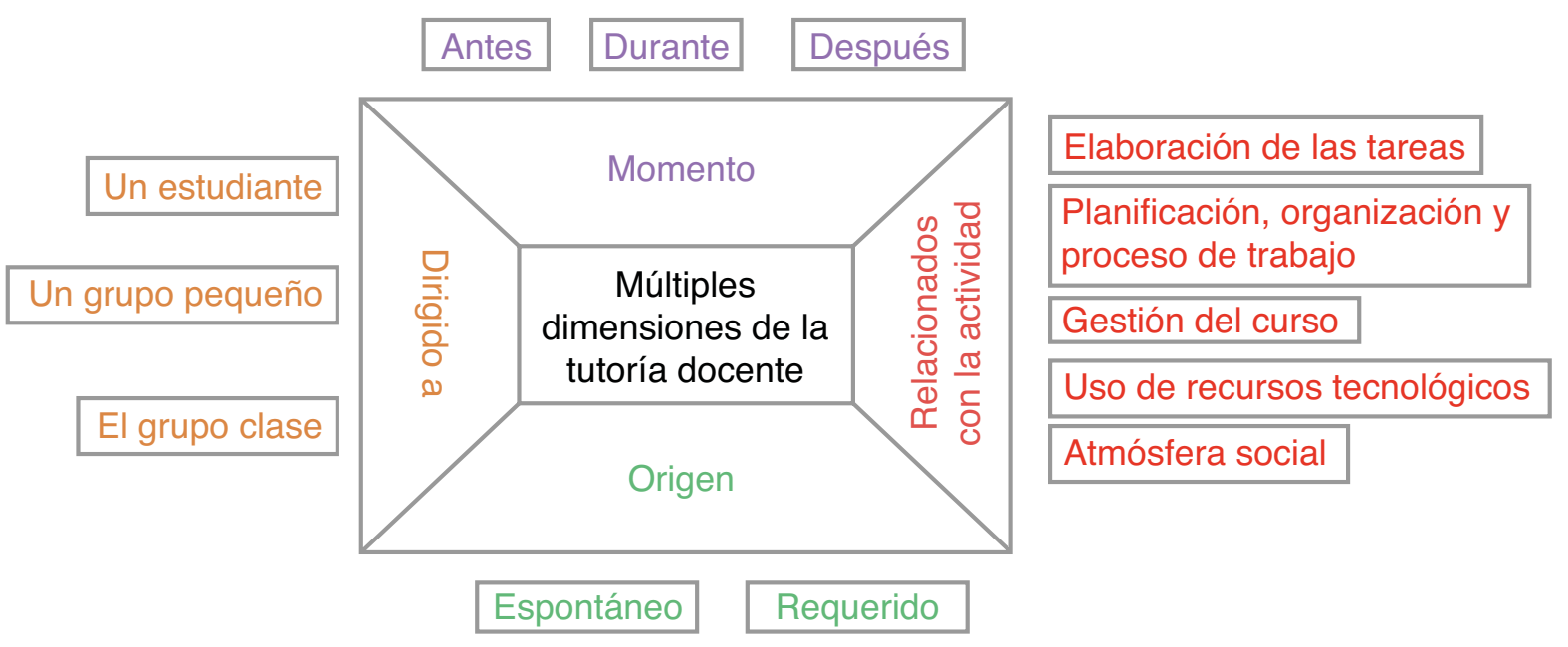

Fuente: Borgobello et al., (2017b).

\section{Formas de enseñar.}

Sanjurjo (2003) considera la selección de las formas de enseñar como ineludible en la enseñanza de cualquier contenido (ver Figura 8). Si bien son difíciles de diferenciar en la exposición presencial, de acuerdo con nuestra experiencia resulta algo más simple diferenciarlas en las clases basadas en la interacción escrita y visual, como se dan en los entornos virtuales. La categoría narración, aquí, fue consignada cuando el docente describía, relataba o contaba. La categoría explicación se consignaba ante la presencia de justificación, reflexión o explicitación de algún término en particular, coincidiendo en algunos casos con la narración. El diálogo se categorizaba ante la presencia explícita de preguntas y respuestas del docente o de los estudiantes. También se categorizaron ejemplos, analogías y metáforas que acompañaban la presencia de conceptos más abstractos, y las apoyaturas visuales como imágenes, tablas o videos. Finalmente, se consignó la categoría ejercicio, cuando las consignas docentes o tareas requeridas así lo explicitaban.

$\boldsymbol{\varepsilon} \| 152$ 
Figura 8| Formas de enseñar. Categorías de análisis basadas en Sanjurjo (2003).

\begin{tabular}{|l|}
\hline Narración \\
\hline Explicación \\
\hline Diálogo e interrogatorio \\
\hline Ejemplo, analogía y metáfora \\
\hline Apoyaturas visuales \\
\hline Ejemplo y Situaciones Problemáticas \\
\hline
\end{tabular}

Fuente: Borgobello et al., (2017b).

El análisis de los datos requirió la construcción de una matriz con los 117 escritos del docente y las categorías correspondientes a cada modelo de análisis. Con la intención de respetar la unicidad decidida por quien escribió cada texto, la unidad de análisis fue el escrito posteado en el espacio virtual en su totalidad. Por esta razón, cada escrito presentaba características de múltiples categorías superpuestas en un mismo sistema de códigos. La decisión metodológica en este caso fue categorizar de modo dicotómico, esto es, presencia o ausencia de cada característica en todos los casos en los que las categorías no fuesen mutuamente excluyentes. El tipo de texto (título de foro, de bloque, de glosario, de tarea, archivo, link, carpeta o mensaje en un foro), el uso de primera persona ya sea del plural o del singular, y la mención al aula presencial fueron las variables activas en el análisis de correspondencias múltiples con clasificación de coordenadas factoriales (Moscoloni, 2005). Las categorías de los modelos teóricos mencionados, esto es, tipos de presencia docente, cognitiva y social (Garrison et al., 2000), dimensiones de la tutoría docente (Onrubia y Engel, 2012) y formas de enseñar (Sanjurjo, 2003) se constituyeron en variables ilustrativas. 
Volumen 3 • Número 1 • enero - junio 2020 • Págs. 129 - 158 •

ISSN: 2389-8798 impreso / ISSN 2539-1445 (En línea) / Tunja, Boyacá (Colombia)

Figura 9| Síntesis del histograma del análisis multivariado de la modalidad de elaboración del guion o scripting docente. $O y E$ = Onrubia y Engel (2012); GAyA = Garrison et al., (2000); $S J=$ Sanjurjo (2003); Ejercicios $=$ Ejercicios y Situaciones Problemáticas; Act. = Relación con la Actividad; Proc. de trab. = Planificación, organización y proceso de trabajo.

\begin{tabular}{|c|c|c|}
\hline Categoria & Caracteristica & Hivlograma \\
\hline \multicolumn{3}{|l|}{ Cluster 1 Texfo de apertura } \\
\hline O,E Dingido a Grupo pequoho & No & 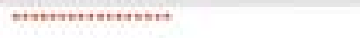 \\
\hline O,E Dingido a Grupo Clase & si & 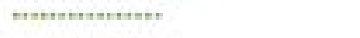 \\
\hline O,E Momento & Antes & 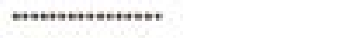 \\
\hline Oye Origen & Esportinoo & 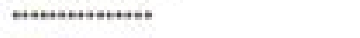 \\
\hline OyE Act Gestion del eurno & Bi & 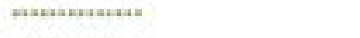 \\
\hline O,E Proc de trab. & $8 i$ & 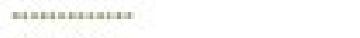 \\
\hline GAyA Presencia Docente & si & 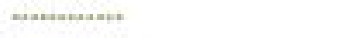 \\
\hline Usa primera persona & si & 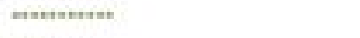 \\
\hline Menciona ol aula trad cional & si & 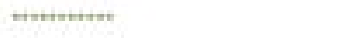 \\
\hline Texto Asociado a & Tibulo de Bloqus & nententus \\
\hline S.J Narracion & si & notrotates \\
\hline S.J Explicadion & Si & $n+m+n+4$ \\
\hline Texto Asociado a & Tibulo de Tarea & neterent \\
\hline Texto Ascciade a & Carpota & nамене \\
\hline \multicolumn{3}{|l|}{ Cluster 2 Textos-Ink } \\
\hline GAyA Pretencia Docente & No & 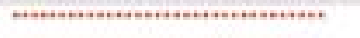 \\
\hline S) Dialogo e interrogatorio & No & 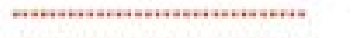 \\
\hline O)E Pres. de trab. & Na & 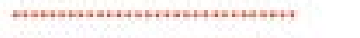 \\
\hline O,E Aet, Elacerscien de Tares & Ne & 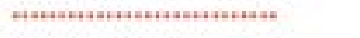 \\
\hline Sij Narracion & No & 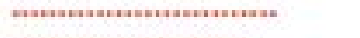 \\
\hline SJ Ejercicios & No & 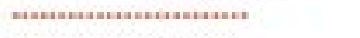 \\
\hline GAyA Presencia Scoial & No & 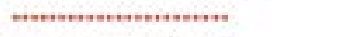 \\
\hline Oye Origen & Espontineo & 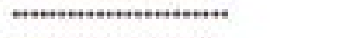 \\
\hline OyE Act Atmonfers social & No & 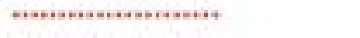 \\
\hline O,E Memento & Artos & 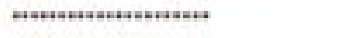 \\
\hline Usa primera persona & Ne & 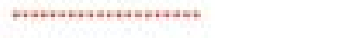 \\
\hline OjE Dingdo a Grupo Clase & Si & 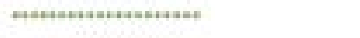 \\
\hline Texto Ascoiado a & Aochivo & 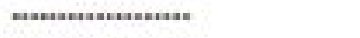 \\
\hline SJ Ejemplo, anslogis y metafora & No & 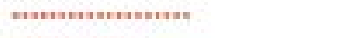 \\
\hline s.j Explicadion & No & 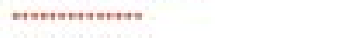 \\
\hline O)E Dirlo do a Grupo pequeho & No & nomentranters \\
\hline Texto Alsociado a & Tralo de Foro & ntrentertst \\
\hline Manciona al aula tradicional & $\mathrm{Ne}$ & nasusenes \\
\hline O)E Aet. Recurses hacroldojeas & Si & покике \\
\hline \multicolumn{3}{|l|}{ Cluster 3 Texfos de tutania } \\
\hline Oye Memento & Durante & 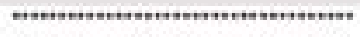 \\
\hline Texto Asociade a & Mentajo on Foro & 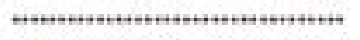 \\
\hline Oye Origen & Respuesta & 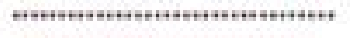 \\
\hline O,E Dingide a Grupo Clase & No & 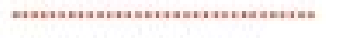 \\
\hline S.J Dialogo e interiogaterio & si & 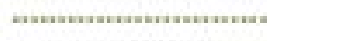 \\
\hline OyE Dinoido a Grupo pequeho & si & 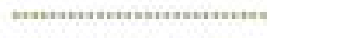 \\
\hline su Ejercicios & si & 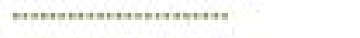 \\
\hline GAyA Presencio Docento & si & 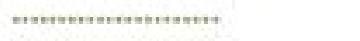 \\
\hline O,E Act. Elaberacion de Tarea & si & 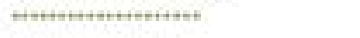 \\
\hline GAyA Pretencia Social & si & 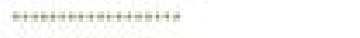 \\
\hline Sa Narracion & Si & 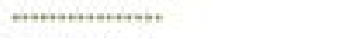 \\
\hline O,E Act. Atmóffera social & si & 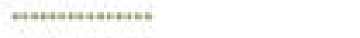 \\
\hline O)E Prec de trab. & 81 & 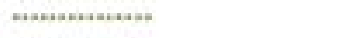 \\
\hline O,E Act. Recurses tecrelogicos & No & 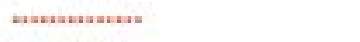 \\
\hline sj Ejomplo. andogla y motafora & si & tertenterent \\
\hline OjE Dingido a Estudiarte & si & mentrm \\
\hline Usa primera rarkena & si & taterte \\
\hline
\end{tabular}


Los escritos del docente se diferenciaron en tres clases o clusters con predominancia de características distintas (véase Figura 9). Al cluster 1 lo denominamos Textos de apertura por sus características de indicaciones generales organizativas dirigidas al inicio o presentación de alguna actividad o etapa del curso. Esta clase representa al $21 \%$ del conjunto de datos (25 escritos), se trataba de textos de anticipación, con presencia docente, espontáneos y de organización del proceso de trabajo (curso y tareas), relacionando los espacios virtual y presencial en los que se narra y explica (las características destacadas en verde y en negro; véanse en la Figura 9).

Al Cluster 2 lo denominamos Textos-link ya que, por lo general, se trataba de algún hipervínculo que llevaba a otro sitio en el que podía o no haber un contexto explicativo que narrara de qué se trataba, pero que carecían de la característica narrativa en el espacio en el que se presentaban. Algunos ejemplos de este tipo de textos eran archivos .pdf denominados solo por apellido (el autor de algún texto que debía leerse en el marco de la materia) o una denominación breve que llevaba a un foro que contenía la consigna de trabajo. Esta clase representa cerca de un tercio del corpus (32\%, 37 textos). Como puede visualizarse en la Figura 9 , los textos coloreados en rojo se caracterizan por la ausencia de categorías fundamentales, dentro de los sistemas de análisis utilizados. Aquí, cabe destacar que el uso de estos recursos se habría garantizado a partir del diálogo dado en clases presenciales en las que se hubiera explicado la razón de cada uno de estos recursos.

Al Cluster 3 lo denominamos Textos de tutoría por sus características de diálogo centrado en la enseñanza y el aprendizaje. Esta clase representa al $47 \%$ de los textos ( 55 escritos). Este grupo de escritos se caracterizó por la interacción centrada en la tarea, en foros basados en la respuesta del docente a estudiantes en particular o grupos pequeños de trabajo. Este tipo de mensajes creaban una atmósfera social, basada en el trabajo académico constructivo con presencia docente (guías y andamiajes) al tiempo que social (uso de nombres propios, saludos, etc.).

\section{Discusión}

A modo de conclusión, nos interesa destacar brevemente algunos temas desde los tópicos trabajados. En primer lugar, la metodología compleja utilizada nos permitió múltiples miradas reflexivas y diálogos sobre hechos que son altamente singulares. Dado que entendemos que enseñar y aprender son acciones situadas y, por ello, conocer y reconocer el 
contexto implican parte del trabajo necesario en la interpretación de los datos. Sin embargo, la ciencia es una construcción que trasciende ese carácter único del aquí y el ahora del dato. Es en ese punto en el que se encuentra nuestro trabajo, entre lo singular y lo más general. Nuestras investigaciones llevan a reconocer polifonías, voces, intereses, diversidad en la enseñanza cuando se utilizan entornos virtuales, por lo que sitúan al docente frente a la necesidad de reconocer esas voces e intereses de su enseñanza, en el contexto institucional que lo condiciona.

En esta línea de trabajo y en este posicionamiento, dentro de la Psicología de la Educación, destacamos la necesidad de volver a pensar la clase (Sanjurjo, 2003), ya no desde la ficción positivista del dato puro (Menin y Temporetti, 2005), sino desde el reconocimiento y los desafíos de la diversidad y el contexto que construimos y nos construye como docentes y como investigadores.

\section{Agradecimientos}

Al PICT17-2013 por el financiamiento de las investigaciones. Andrea Espinosa, Liliana Sanjurjo, Mariana Sartori, Mariano Castellaro, Nadia Peralta, Natalia Monjelat, Gabriela Raynaudo y Néstor Roselli por el trabajo conjunto en los diseños, en las discusiones y en el análisis de datos.

\section{Referencias}

Achilli, L. A. (2005). Investigar en la Antropología Social. Los desafíos de transmitir un oficio. Rosario: Laborde.

Archenti, N. (2007). El papel de la teoría en la investigación social. En A. Marradi, N. Archenti y J.I. Piovani (Eds.) Metodología de la Ciencias Sociales (pp.61-70). Buenos Aires: Emecé.

Boelens, R., De-Wever, B. \& Voet, M. (2017). Four key challenges to the design of blended learning: A systematic literature review. Educational Research Review, 22(1), 1-18.

Borgobello, A. y Peralta, N. (2011). Funciones tutoriales y auxiliares de docencia. Análisis de las reglamentaciones vigentes en la UNR, Argentina. Revista Mexicana de orientación educativa, 7(20), 48-55.

Borgobello, A. y Roselli, N. D. (2016). Rendimiento académico e interacción sociocognitiva de estudiantes en un entorno virtual. Educação E Pesquisa, 42(2), 359-374.

$\boldsymbol{\epsilon} \mid 156$ 
Borgobello, A., Peralta, N. S. y Roselli, N. D. (2010a). El estilo docente universitario en relación al tipo de clase y a la disciplina enseñada. Liberabit Revista de Psicología, 16(1), 7-17.

Borgobello, A., Peralta, N. S. y Roselli, N. D. (2010b). La función tutorial en el sistema educativo formal: una posible clasificación de sus modalidades. Pensando Psicología, 6(10), 111-121.

Borgobello, A., Raynaudo, G. \& Peralta, N. (2014). Characterizing papers about 'blended learning': an unconsolidated field? Revista IRICE, 26(1), 37-66.

Borgobello, A., Roselli, N. \& Peralta, N. (2013). Interaction among experience, teaching performance and student's learning at university level. Revista Estudos de Psicologia, 30(2), 169-176.

Borgobello, A., Sartori, M. y Espinosa, A. (2017a). Implicancias educativas de análisis estructurales y de contenido de la interacción socio-cognitiva en entornos virtuales en casos blended learning. Ponencia presentada en el VIII Encuentro Regional y Latinoamericano "La Universidad como objeto de Investigación", Universidad Nacional del Litoral, Santa Fe, Argentina.

Borgobello, A., Sartori, M. y Espinosa, A. (2017b). Desafíos, descripciones y reflexiones acerca de la incorporación de TIC en un contexto universitario al sur del mundo. Boletín Científico Sapiens Research, 7(2), 39-50.

Borgobello, A., Espinosa, A., \& Sartori, M. (2018). Six Theoretical- Methodological Approaches to Analyze written texts in a Year-long Blended Learning Course. Revista Iberoamericana de Psicología, 11(3), 139-152.

Borgobello, A., Sartori, M. y Roselli, N. D. (2016). ¿Cómo interactuamos aquí y allá? Análisis de expresiones verbales en una clase presencial y otra virtual a partir de dos sistemas de codificación diferentes. Revista de La Educación Superior, 45(179), 95-110.

Borgobello, A., Sartori, M., y Sanjurjo, L. (2018). Concepciones de docentes sobre los estudiantes y sus prácticas pedagógicas. Educación y Educadores, 21(1), 27-48. https://doi.org/10.5294/edu.2018.21.1.2

Bruner, J. (1997). La educación, puerta de la cultura. Madrid: Aprendizaje Visor.

Bruner, J. (2005). La cultura en el laberinto de la mente. Aproximación filosófica a la "psicología cultural" de Jerome Bruner. Buenos Aires: Miño y Dávila. 
Volumen 3 • Número 1 • enero - junio 2020 • Págs. 129 - 158 •

ISSN: 2389-8798 impreso / ISSN 2539-1445 (En línea) / Tunja, Boyacá (Colombia)

Camillioni, A. W. (2016). La pluralidad de campos en la investigación sobre la enseñanza en la educación superior. En M. Insaurralde (Comp.), La enseñanza en la educación superior. Investigaciones, experiencias y desafios (pp.51-62). Buenos Aires: Noveduc.

Garrison, D. R., Anderson, T. \& Archer, W. (2000). Critical inquiry in a text-based environment: Computer conferencing in higher education. The Internet and Higher Education, 2(2-3), 87-105.

Maggio, M. (2016). Enriquecer la enseñanza. Los ambientes con alta disposición tecnológica como oportunidad. Buenos Aires: Paidós.

Moscoloni, N. (2005). Las Nubes de Datos. Métodos para analizar la complejidad. Rosario, Argentina: UNR Editora.

Onrubia, J. \& Engel, A. (2012). The role of teacher assistance on the effects of a macro-script in collaborative writing tasks. International Journal of Computer-Supported Collaborative Learning, 7(1), 161-186.

Piovani, J. I. (2007). Otras formas de análisis. En A. Marradi, N. Archenti y J. I. Piovani (Eds). Metodología de las Ciencias Sociales (pp. 287-298). Buenos Aires: Emecé.

Roselli, N. D., Dominino, M. y Peralta, N. S. (2010). Influencia del tipo de tarea sobre la interacción colaborativa en equipos virtuales. Revista de Psicología General y Aplicada, 63, 97-119.

Sanjurjo, L. O. (2003). Las formas básicas de enseñar. En L.O. Sanjurjo y X. Rodríguez (Eds.), Volver a pensar la clase (pp. 41-132). Rosario: Homosapiens.

Temporetti, F. y Menin, O. (2005). Reflexiones acerca de la escritura científica. Investigaciones, proyectos, tesinas y monografías. Rosario: Homo Sapiens.

Ynoub, R. C. (2007). El proyecto y la metodología de la investigación. Buenos Aires: Cengage Learning. 